Pol. Con. (Edición núm. 6) Vol. 2, No 4 Abril 2017, pp. 101-110

ISBN: 2550 - 682X

DOI: 10.23857/pc.v2i4.106

Recepción: 12/ 09/ 2016

Aceptación: 31 / 01/ 2017

Publicación: 29/ 04/2017

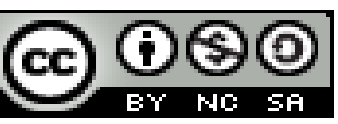

Ciencias de la salud

Artículo de investigación

\title{
Epidemiología de la caries dental en adolescentes de un consultorio odontológico
}

Epidemiology of dental caries in adolescents in a dental practice
Epidemiologia da cárie dentária em adolescentes de um consultório odontológico

\author{
Nicolle V. Muñoz-Macías I \\ nicolle@hotmail.com
}

\author{
Maholy D. Muñoz Macías II \\ maholymunozm@hotmail.com
}

Julio C. Jimbo-Mendoza III juliojimbomendoza@gmail.com

Correspondencia: albamariamc@ hotmail.com

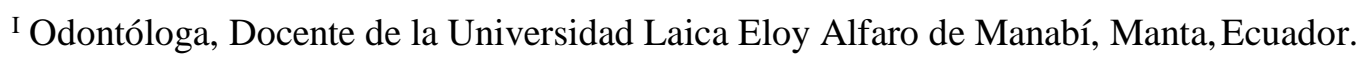

${ }^{\text {II } O d o n t o ́ l o g a, ~ D o c e n t e ~ d e ~ l a ~ U n i v e r s i d a d ~ L a i c a ~ E l o y ~ A l f a r o ~ d e ~ M a n a b i ́, ~ M a n t a, ~ E c u a d o r . ~}$

III Magister en Salud Publica Mención Gerencia de los Servicios de Salud, Doctor en Odontología, Diploma Superior en Educación Universitaria por Competencias, Docente de la Universidad Laica Eloy Alfaro de Manabí, Manta, Ecuador. 


\section{Resumen}

La caries dental se describe como una secuencia de procesos de destrucción localizada en los tejidos duros del diente que evoluciona en forma progresiva e irreversible. La misma comienza en la superficie y luego avanza en profundidad. Se realizó un estudio descriptivo y transversal en adolescentes de 12 a 14 años de edad que asistieron al consultorio privado de la ciudad de Manta, durante el trimestre de enero a marzo del 2016, con vistas a identificar los factores de riesgo que favorecieron la aparición de la caries dental .La población de estudio estuvo formado por los 100 adolescentes que asistieron al consultorio. Entre los principales resultados se obtuvo que los pacientes pertenecientes al grupo III fueron los más representativos con un total de 48 , para $48.0 \%$. El grupo de edad fue la de 12 años (52.0\%). La enfermedad de mayor prevalencia fue la caries dental. Factores de riesgo presente: higiene bucal deficiente, ingestión de alimentos azucarados, experiencia anterior. Atendiendo a los resultados observados se considera necesaria una proyección futurista en relación con las actividades preventivas curativas para disminuir los factores de riesgo en la etapa de la adolescencia

Palabras clave: adolescentes, caries dental, factores de riesgo.

\section{Abstract}

Dental caries is described as a sequence of processes of destruction located in the hard tissues of the tooth that progressively evolves and irreversible. It begins at the surface and then advances in depth. A descriptive and cross-sectional study was conducted in adolescents aged 12 to 14 years attending the private practice of the city of Manta, during the quarter of January to March of 2016, in order to identify the risk factors that favored the appearance of Dental caries. The study population consisted of the 100 adolescents who attended the clinic. Among the main results it was obtained that patients belonging to group III were the most representative with a total of 48 , to $48.0 \%$. The age group was 12 years old $(52.0 \%)$. The most prevalent disease was dental caries. Present risk factors: poor oral hygiene, ingestion of sugary foods, previous experience. In view of the observed results, it is considered necessary a futuristic projection in relation to preventive curative activities to reduce the risk factors in the stage of adolescence

Key words: adolescents, dental caries, risk factors.. 


\section{Resumo}

Cárie dentária é descrito como uma sequência de processos de destruição localizadas em tecidos de dentes rígidos que evoluem progressivamente e de forma irreversível. Ela começa na superfície e, em seguida, desenvolvido em profundidade. Um estudo descritivo transversal em adolescentes de 12 a 14 anos que participaram do escritório particular da cidade de Manta, durante o trimestre janeiro a março 2016, com vista à identificação de fatores de risco que favorecem o aparecimento foi feito a cárie dentária .A população do estudo consistiu de 100 jovens que frequentaram a clínica. Os principais resultados obtidos para os pacientes pertencentes ao grupo III eram o mais representativa com um total de 48 a 48,0\%. O grupo de idade foi de 12 anos $(52,0 \%)$. A doença foi a cárie dentária mais prevalente. fatores de risco presentes: má higiene oral, ingestão de alimentos açucarados, experiência anterior. Com base nos resultados observados uma projecção futurista é considerado necessário em ligação com as actividades preventivas de cura para reduzir factores de risco na adolescência.

Palavras chave: adolescentes, cárie dentária, fatores de risco.

\section{Introducción}

La Organización Mundial de la Salud (OMS) ha definido la caries dental como un proceso localizado de origen multifactorial que se inicia después de la erupción dentaria, determinando el reblandecimiento del tejido duro del diente que puede evolucionar hasta la formación de una cavidad. Si no se atiende oportunamente, afecta la salud general y la calidad de vida de los individuos. ${ }^{1}$

La caries dental junto con la enfermedad periodontal, constituyen el mayor porcentaje de morbilidad dentaria durante toda la vida de un individuo. Afecta a personas de cualquier edad, sexo y raza; teniendo una mayor presencia en sujetos de bajo nivel socioeconómico. Esta situación guarda relación directa con un deficiente nivel educativo, una mayor frecuencia en el consumo de alimentos ricos en sacarosa entre las comidas y el tiempo en que estos permanecen en la boca. ${ }^{1}$

En la formación de la caries dental se involucran según Newbrun varios factores: huésped, bacterias, sustrato (azúcares fermentables), así como el tiempo. En este proceso es necesario que 
las condiciones de cada factor sean favorables, es decir, un huésped susceptible, una flora oral cariogénica y un sustrato apropiado, que deberá estar presente durante un período determinado de tiempo. $^{2}$

El concepto de riesgo ocupa un lugar central en la atención primaria de salud por las posibilidades de predecir un acontecimiento, tanto en el plano de la enfermedad como en el de la salud, lo cual ofrece a la atención primaria de salud bucal un nuevo instrumento para establecer prioridades y tomar decisiones. $^{2}$

Por otra parte, se conoce que en cuanto a la relación caries-dieta existen pruebas más que suficientes para establecer como un hecho que la ingestión de sacarosa, la frecuencia del consumo y la cantidad induce a placa y caries dental ${ }^{2}$.

Representar la distribución de la caries dental en poblaciones no es un propósito reciente. Las preocupaciones de Émile Magitot en Francia, en el siglo XIX, por hacer un mapa epidemiológico de la caries de acuerdo con los climas de las diferentes regiones son un antecedente para ilustrarlo ; pero, al margen de esa serie de este tipo de iniciativas, es posible decir que la institucionalización de la representación mundial de la situación de salud oral con relación a la caries dental se puede ubicar en la segunda mitad de la década de los sesenta del siglo XX . La contingencia particular que va a permitir este desarrollo es la creación de la Unidad de Salud Oral de la OMS. ${ }^{3}$

Existe información relacionada a la prevalencia de caries dental en Ecuador correspondiente a junio del 2014, donde se encontró que en niños de 3 a 11 años de edad existe una prevalencia de $62,39 \%$ y en individuos de 12 a 19 años de edad una prevalencia de 31,28\%. En Ecuador existe programa que comenzó el 2013 con miras hasta el 2017, llamado "Plan Nacional del Buen Vivir", donde interviene el Ministerio de Salud Pública y el Instituto Ecuatoriano de Seguridad Social, siendo uno de los objetivos el levantar el perfi epidemiológico de la población. Otro de los esquemas planeados en dicho programa es la atención por "ciclos de vida", basados en la vigilancia, prevención y control de enfermedades correspondientes a grupos de: gestantes, niños de 0 a 5 años y escolares de 6 a 14 años. Dicho programa posee una presencia importante a nivel escolar, contando con el apoyo de empresas privadas, así como la ejecución del programa de la 
"Lonchera saludable". También existen otros beneficios como: rehabilitación para gestantes y diagnóstico y prevención en escolares de $2^{\circ}$ año de nivel básico.

Este programa tiene como finalidad la participación y vinculación con la comunidad. ${ }^{4}$

La adolescencia ha sido definida tradicionalmente como la etapa de tránsito entre la niñez y la adultez, sin embargo, en la actualidad existe consenso en cuanto a considerar la adolescencia como un momento clave en el proceso de socialización del individuo. ${ }^{2}$

Es común en esta etapa la aparición de conflictos en su relación con los adultos que agudizan la llamada «crisis de la adolescencia» y que conlleva en no pocas ocasiones a la ruptura de reglas establecidas hasta ese momento como forma de rebeldía, por lo que es usual el abandono de hábitos de higiene que habían imperado durante la etapa precedente. ${ }^{2}$

Con todos los argumentos expuestos anteriormente consideramos de gran utilidad la caracterización de nuestra población adolescente (12-14 años) y su clasificación, teniendo en cuenta los factores de riesgo que sean posibles identificar y evaluar en nuestro medio, para en un futuro implementar estrategias educativas que promuevan un cambio de conducta y reducir la proporción de adolescentes con caries dental.

\section{Material y método}

Se realizó un estudio descriptivo y transversal en adolescentes de 12 a 14 años de edad que asistieron al consultorio privado de la ciudad de Manta, durante el trimestre de enero a marzo del 2016, con vistas a identificar los factores de riesgo que favorecieron la aparición de la caries dental .La población de estudio estuvo formado por los 100 adolescentes que asistieron al consultorio privado de la ciudad de Manta, cuyos padres, tutores o representantes dieron su consentimiento para la investigación.

Se realizó un examen clínico-bucal a los adolescentes por medio del índice COP-D de Klein y Palmer para dientes permanentes.

Entre las variables analizadas figuraron: edad, sexo, magnitud de la afección (morbilidad: presencia de caries y obturaciones y pérdida dentaria, ya fuera por caries o extracción indicadas), 
Se tuvo en cuenta la cantidad de factores de riesgos presentes (higiene bucal deficiente, ingestión de alimentos azucarados, agentes fluorurados no utilizados)

La información fue recogida a través de la anamnesis, la inspección visual y la exploración clínica (táctil), con la ayuda de un equipo de diagnóstico para cada adolescente, que incluía espejo bucal y explorador; luego se introdujo en la planilla confeccionada a tal efecto. Como métodos teóricos se emplearon el análisis y la síntesis, que posibilitaron la interpretación conceptual de los datos empíricos encontrados.

\section{Resultado y discusión}

Tabla Clasificación epidemiológica según edad

\begin{tabular}{|c|c|c|c|c|c|c|c|c|}
\hline \multirow{2}{*}{ Edad } & \multicolumn{2}{|c|}{ Grupo I I } & \multicolumn{2}{c|}{ Grupo III } & \multicolumn{2}{c|}{ Grupo IV } & \multicolumn{2}{c|}{ Total } \\
\cline { 2 - 9 } & No & $\%$ & No & $\%$ & No & $\%$ & No & $\%$ \\
\hline 12 & 10 & 25 & 25 & 52 & 4 & 40 & 39 & 39 \\
\hline 13 & 12 & 30 & 12 & 25 & 2 & 16.6 & 26 & 26 \\
\hline 14 & 18 & 45 & 11 & 22.9 & 6 & 50 & 35 & 35 \\
\hline Total & 40 & 40 & 48 & 48 & 12 & 12 & 100 & 100 \\
\hline
\end{tabular}

Del total de pacientes examinados, se efectuó una distribución según la clasificación epidemiológica dada a la presencia de factores de riesgos que incidió en esta población, y se obtuvo que los pacientes pertenecientes al grupo III fueron los más representativos con un total de 48, para $48.0 \%$. El grupo de edad fue la de 12 años (52.0\%). (tabla ). La enfermedad de mayor prevalencia fue la caries dental.

La OMS define que un factor de riesgo es cualquier rasgo, característica o exposición de un individuo que aumente su probabilidad de sufrir una enfermedad o lesión. Entre los factores de riesgo más importantes cabe citar la insuficiencia ponderal, las prácticas sexuales de riesgo, la hipertensión, el consumo de tabaco y alcohol, el agua insalubre, las deficiencias del saneamiento y la falta de higiene. ${ }^{6}$ 
El mayor número de pacientes, 85 de ellos, para $85.0 \%$, eran de moderado riesgo y en el alto riesgo 15, para $15.0 \%$. La edad de 14 años fue la más afectada, con $49.0 \%$, y predominó el sexo femenino, pues además presentaron casi todos los factores de riesgos asociados a la aparición de la caries dental.

Se destacó la deficiente higiene bucal en 75 adolescentes que refirieron que realizaban el cepillado una vez al día, la ingestión de alimentos azucarados entre comidas. La deficiente higiene bucal predominó en todos los grupos de edades de forma similar, confirma que esta puede estar constituyendo un riesgo importante en los jóvenes, tal como también lo afirman otros autores. $^{7,8,9}$,

La clasificación de riesgo a caries dental en la población estudiada evidenció la necesidad de tratamiento y acciones preventivas para modificar algunos factores de riesgo y promover un cambio de conducta que posibilite la reducción de la proporción de adolescentes con caries dental

Estos resultados también son semejantes a los que notificara Casanova, ${ }^{10}$ en una investigación llevada a cabo en escolares mexicanos, demostró que la deficiente higiene bucal es un factor asociado a la pérdida del primer molar permanente. Otro estudio realizado en la región sur del estado de Tamaulipas, México por Vázquez-Rodríguez $\mathrm{E}^{11}$ y colaboradores con la finalidad de determinar la prevalencia de la caries dental en adolescentes y su asociación con el género, escolaridad materna y el estatus socioeconómico familiar entre sus resultados demostró que de un total de 1.893 adolescentes que fueron estudiados la caries dental se diagnóstico en 48,2\% de los adolescentes.

En la actualidad se observa una tendencia mundial en la disminución de las caries dental, fundamentalmente en los grupos más favorecidos; algunas de las razones que han incidido en esta disminución del índice de COP-D son: aumento del número de personas con mejoras socioeconómicas, presencia de programas de fluoruracion, cambios de los perfiles del consumo de carbohidratos, transformación de la practica odontológica: curativa a preventiva, ente otros ${ }^{12}$ Al analizar el índice COP-D en los tres grupos prevaleció los dientes obturados resaltándose la labor curativa en el servicio. El sexo femenino fue el más representativo. La prevalencia en los niños de 12 años fue moderada (5.0) de acuerdo a la clasificación de la OSM. Estudio realizado 
en un consultorio Barrio Federación, de la República Bolivariana de Venezuela por Seguén Hernández $\mathrm{J}{ }^{9}$ y colaboradores sus resultados coinciden con esta investigación.

Respecto a la experiencia anterior de caries en esta casuística, el $75.0 \%$ de los adolescentes estudiados resulto positiva, tal resultado concordó con lo expresado por Wandera A 13 y Almeida et al $^{14}$ que los niños con caries de la primera infancia, presentan el doble de dientes cariados, obturados y perdidos a los 4 y 6 años de edad, que los que no las poseen.

Para dar por concluido, atendiendo a los resultados observados se considera necesario una proyección futurista en relación con las actividades preventivas curativas para disminuir los factores de riesgo en la etapa de la adolescencia, e incrementar el conocimiento sobre salud bucal, con énfasis en la higiene bucal y dieta cariogénica, a través de programas educativos en las diferentes instituciones escolares y centros de atención odontológica.

Referencias bibliográficas.

1- Epidemiología de caries dental y factores de riesgo asociados a la dentición primaria en preescolares. 2009. Revista ADM LXV( 3)

2- Quintero Ortiz Julia E, Méndez Martínez María J, Medina Seruto María, Gómez Mariño Mercedes. Factores de riesgo y caries dental en adolescentes de 12 a 15 años. AMC . 2008 [citado 20 Mayo 202016 ] ; 12( 3 ): . Disponible en: http://scielo.sld.cu/scielo.php?script=sci_arttext\&pid=S1025$02552008000300004 \& \operatorname{lng}=\mathrm{es}$

3- Duque Naranjo C, Mora Díaz I . La representación de la epidemiología de la caries en el mundo a través de mapas. 2012. 31(66);41-50.

4 Epidemiología de la caries dental en América Latina. Relatorios de la mesa de representantes de sociedades de Odontopediatría de los países Latinoamericanos. .Revista Odontología odontopediatria latinoameicana 2014. [citado 20 Mayo 20 2016]; 4(2). Disponible en: http://www.revistaodontopediatria.org/ediciones/2014/2/art-4/ 
5- Franco Cortés A.M., Guzmán Zuluaga I.C., Gómez Restrepo A.M., Ardila Medina C.M.. Reemergencia de la caries dental en adolescentes. Av Odontoestomatol [Internet]. 2010 [citado 20 mayo 2016] ; 26( 5 ): 263-270. Disponible en: http://scielo.isciii.es/scielo.php?script=sci_arttext\&pid=S0213$12852010000500006 \& \operatorname{lng}=\mathrm{es}$.

6- Factores de riesgo OMS. 2016. [citado 20 Mayo 20 2016]. Disponible en: http://www.who.int/topics/risk_factors/es/

7- Irigoyen M, Zepeda A, Sánchez L. Prevalencia e incidencia de caries dental y hábitos de higiene bucal en un grupo de escolares del sur de la Ciudad de México.Revista ADM 2001:53 (8):98-104.

8- Lulic-Dukic O, Juric H. Factors predisposing to early childhood caries (ECC) inchildren of pre-school age in the city of Zagreb, Croatia. Coll Antropol 2002;25(1):297-302.

9- Seguén Hernández, J Arpízar Quintana, R Chávez González Z, López Morata B, Coureaux Rojas L . Epidemiología de la caries en adolescentes de un consultorio odontológico venezolano. MEDISAN 2010;14(1):42.

10- Casanova Rosado AJ. Factores asociados a la pérdida del primer molar permanente en escolares de Campeche, México, 2004.

11- Vázquez-Rodríguez E ,1 Calafell-Ceballos RA,2Barrientos-Gómez M ,3Lin Ochoa D , Saldívar-González A ,3.Cruz-Torres D, Vázquez-Nava F,4. Torres-Ferman . Prevalencia de caries dental en adolescentes: Asociación con género, escolaridad materna y estatus socioeconómico familiar. 2011 Revista CES Odontología 24 - 1

12- Rosales Sosas M . Epidemiológicas de las enfermedades bucales más frecuentes . Cap I . Estomatología General Integral . Editrial Ciencias Medicas 2013 
13- Wandera A, Bhakta S, Barker T. Caries prediction and indicators using a pedriatic risk assessment teaching tool. ASD J Dent Chil 2004; 67(6):408-12,375.

14 Almeida AG, Roseman MM, Sheff M. Future caries susceptibility in children with early chilhood caries following treatment under general anesthesia. Pediatr Dent 2000; 22(4):302-6. 